\title{
PLANTIO DIRETO E O AUMENTO NO CONTEÚDO DE MATÉRIA ORGÂNICA DO SOLO EM PEQUENAS PROPRIEDADES RURAIS NO MUNICÍPIO DE TEUTÔNIA
}

\author{
NO TILLAGE AND INCREASE ON SOIL ORGANIC MATTER CONTENT \\ IN SMALL FARMS OF TEUTONIA COUNTY, SOUTHERN BRAZIL
}

\author{
Cimélio Bayer ${ }^{1}$ Nestor Guilherme Scheneider ${ }^{2}$
} \begin{abstract}
Este estudo teve por objetivo avaliar o efeito da uti-
lização de diferentes sistemas de manejo sobre os teores de RESUMO matéria orgânica do solo no município de Teutônia, na Região das Encostas Basálticas do RS. As amostras de solo foram retiradas em quatro propriedades rurais, nas profundidades de 0-2,5, 2,5-5,0, 5,0-10,0 e 10,0-20,0cm em áreas de campo nativo e de lavouras em preparo convencional e plantio direto. Uma área de mata foi amostrada e utilizada como referência da condição natural do solo na região. Comparativamente ao solo de mata, ocorreu uma redução em torno de 60-70\% dos teores de matéria orgânica na camada de $0-2,5 \mathrm{~cm}$, e na média de $50 \%$ na camada de 0-10,0cm do solo com a utilização do preparo convencional. A utilização de plantio direto, durante 3-7 anos, resultou num aumento nos teores de matéria orgânica entre $25-108 \%$ na camada de 0-2,5cm, e de $18-52 \%$ na camada de 0-10cm, comparativamente ao preparo convencional.
\end{abstract}

Palavras-chave: matéria orgânica, manejo do solo, conservação do solo.

\section{SUMMARY}

The objetive of this study was to evaluate the effect of management systems on soil organic matter contents. Soil samples were collected at 0-2.5, 2.5-5.0, 5.0-10.0 and 10.0$20.0 \mathrm{~cm}$ depth in native grassland area and croplands under conventional and no tillage systems. Soil sample collected from a forest area were used as reference of the original soil condition of the region. The use of conventional tillage decreased soil organic matter contents approximately $60-70 \%$ in the $0-2.5 \mathrm{~cm}$ soil layer, and approximately $50 \%$ in the $0-10.0 \mathrm{~cm}$ soil layer, relativelly to the forest soil. The use of no tillage for 3-7 years resulted in increases of soil organic matter content of $25-108 \%$ in $0-2.5 \mathrm{~cm}$ soil layer, and $18-52 \%$ in $0-10 \mathrm{~cm}$ soil layer, comparativelly to the conventional soil tillage.

Key words: organic matter, soil management, soil conservation.

A região das encostas basálticas do $\mathrm{RS}$ compreende cerca de $20 \%$ da área agrícola produtora do Estado, com a ocorrência basicamente de pequenas propriedades rurais com grande diversificação de atividades. O relevo da região é suave ondulado a ondulado, e a pequena extensão das propriedades, normalmente, resulta no uso do solo fora da sua aptidão agrícola. Isto, associado à falta de cobertura do solo pela utilização de métodos de preparo com aração e gradagem, culmina num intenso processo erosivo nas áreas cultivadas. A partir da década de 80 tem se despertado a atenção em relação à utilização de sistemas de manejo conservacionistas do solo, os quais têm como objetivo principal o controle da erosão, ocorrendo, entretanto, uma série de modificações na dinâmica do sistema solo, que determina a sua capacidade produtiva. Apesar da importância econômica da agricultura da região, poucos são os trabalhos de pesquisa desenvolvidos no sentido de se avaliar o efeito destes sistemas de manejo em nível regional.

Nesse sentido, realizou-se este estudo, o qual teve por objetivo avaliar o efeito de sistemas de manejo do solo sobre os teores de matéria orgânica. Segundo DORAN \& PARKIN (1994), por ser um atributo dinâmico e ter grande influência sobre as condições químicas, físicas e biológicas do solo, a matéria orgânica é um parâmetro adequado para avaliar o efeito dos sistemas de manejo do solo sobre a capacidade produtiva e, portanto, um índice do efeito dos sistemas de manejo na sustentabilidade da atividade agrícola na região.

\footnotetext{
${ }^{1}$ Engenheiro Agrônomo, Professor, Departamento de Solos, Faculdade de Agronomia da UDESC, CP 281, 88520-000, Lages, SC. E-mail: bayer@cav.udesc.br. Autor para correspondência.

${ }^{2}$ Engenheiro Agrônomo, Assessor Técnico do Clube Amigos da Terra-Regional Teutônia, Teutônia, RS

Recebido para publicação em 16.06.97. Aprovado em 29.07.98
} 
Amostraram-se áreas de agricultores no município de Teutônia, RS, região Fisiográfica das Encostas Basálticas. O solo (Terra roxa estruturada) foi amostrado em quatro propriedades rurais, em área de campo nativo, lavoura sob preparo convencional e plantio direto. As áreas sob campo nativo encontravam-se há mais de 30 anos nesta condição. As áreas sob preparo convencional encontravam-se há 24, 30, 26 e 33 anos nesta condição, e as áreas sob plantio direto há $4,5,7$ e 3 anos, nas propriedades 1, 2, 3 e 4, respectivamente. Os locais amostrados apresentavam relevo suave ondulado, sendo as amostras coletadas na parte baixa da pendente. Foi amostrada uma área de mata para servir como parâmetro da condição natural do solo.

As amostras foram coletadas manualmente nas profundidades de $0-2,5 \mathrm{~cm}, 2,5-5,0 \mathrm{~cm}$, $5,0-10,0 \mathrm{~cm}$ e $10,0-20,0 \mathrm{~cm}$ com o auxílio de trados com diferentes diâmetros para evitar a contaminação entre amostras. Cada amostra final foi composta por três subamostras. As amostras de solo foram secas em estufa $\left(60^{\circ} \mathrm{C}\right)$ durante três dias, moídas até passarem em peneira de malha $0,5 \mathrm{~mm}$, sendo posteriormente analisadas quanto aos seus teores de carbono orgânico total, segundo metodologia apresentada em TEDESCO et al. (1995).

Os resultados obtidos são apresentados na Figura 1. Comparativamente ao solo sob mata, observou-se uma redução em torno de $60-70 \%$ dos teores de matéria orgânica na camada superficial (0$2,5 \mathrm{~cm}$ ) do solo, com a utilização de lavouras em preparo convencional. Em média, na camada de 0$10,0 \mathrm{~cm}$ ocorreu uma redução de $50 \%$ dos teores de matéria orgânica. A grande diminuição dos teores de matéria orgânica observada foi superior à expectativa inicial, sendo semelhante às observadas nas regiões Norte e Centro-Oeste do Brasil (CERRI et al., 1996), onde as altas temperaturas e precipitações determinam elevadas taxas de decomposição da matéria orgânica. Na região das Encostas Basálticas, as maiores perdas de matéria orgânica, por erosão, em preparo convencional, devido ao relevo declivoso, devem assumir uma importância relativa maior na redução dos teores de matéria orgânica do solo do que em outras regiões.

A alteração do uso e/ou manejo do solo, substituindo as lavouras sob preparo convencional por campo nativo ou plantio direto, resultaram numa recuperação dos teores de matéria orgânica, provavelmente devido às menores perdas por erosão e redução da taxa de decomposição da matéria orgânica. A utilização do plantio direto, durante 3-7 anos, resultou num incremento nos conteúdos de

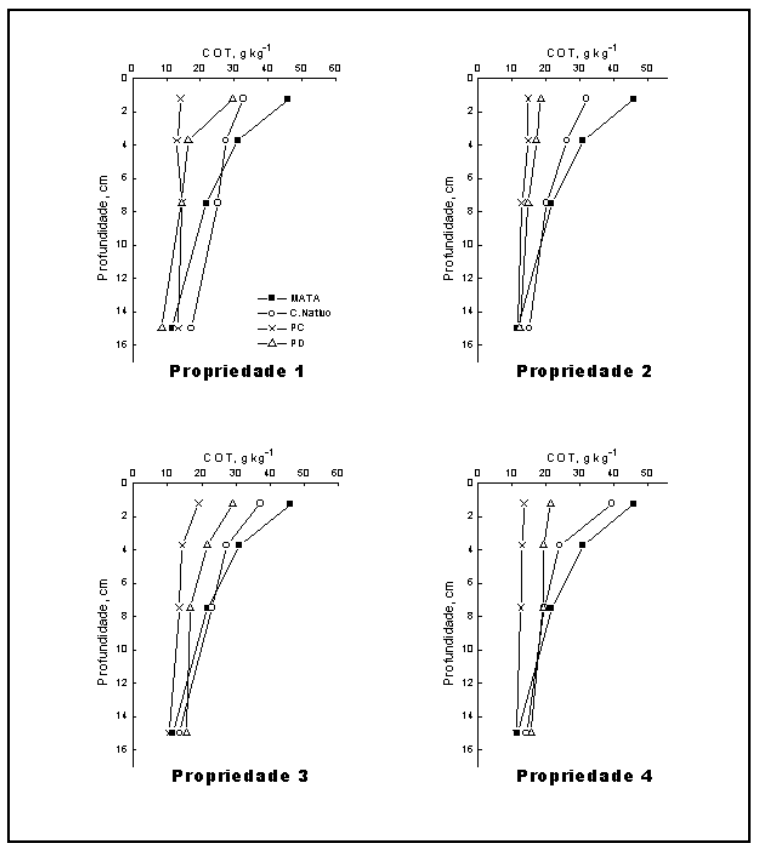

Figura 1 - Efeito dos sistemas de manejo sobre os teores de carbono orgânico do solo, em quatro propriedades rurais do município de Teutônia, Região das Encostas Basálticas do RS.

matéria orgânica entre 25 e $108 \%$ na camada de 0 $2,5 \mathrm{~cm}$, e de $18-52 \%$ na camada de $0-10 \mathrm{~cm}$, comparativamente ao solo sob preparo convencional.

Nas áreas sob campo nativo, a matéria orgânica deve estar próxima de um conteúdo estável, devido ao período de 30 anos sob este manejo. Já nas áreas sob plantio direto, devido ao curto período decorrido de utilização do sistema, a matéria orgânica encontra-se num processo de acúmulo, cuja taxa irá reduzir gradualmente a partir dos próximos anos, até atingir um conteúdo estável, determinado pela relação entre as taxas de adição e de perda de matéria orgânica do solo.

\section{REFERÊNCIAS BIBLIOGRÁFICAS}

CERRI, C.C., BERNOUXS, M., VOLKOFF, B., et al. Dinâmica do carbono nos solos da Amazônia. In: ALVAREZ, V.H., FONTES, L.E.F., FONTES, M.P.F. O solo nos grandes Domínios morfoclimáticos do Brasil e o desenvolvimento sustentado. Viçosa: SBCS/UFV/Depto Solos, 1996. Cap. 3, p. 61-69.

DORAN, J.W., PARKIN, T.B. Defining and assessing soil quality. In: DORAN, J.W., COLEMAN, D.C., BEZDICEK, D.F.and STEWART, B.A. Defining soil quality for a sustainable environment. Madison: SSSA/ASA, Special Publication $\mathrm{N}^{\circ}$ 35,1994. Cap. 1, p. 3-21.

TEDESCO, M.J., GIANELLO, C., BISSANI, C.A., et al. 1995 Análise de solo, plantas e outros materiais. 2 ed. Porto Alegre: Departamento de Solos, UFRGS, 174 p. (Boletim Técnico, 5). 